\title{
Assessing vascular function using dynamic retinal diameter measurements: A new insight on the endothelium
}

\author{
Rebekka Heitmar; Robert James Summers
}

Aston University, School of Life and Health Sciences, Birmingham

\section{Introduction}

Reliable assessment of endothelial function is important for the diagnosis, risk prediction and treatment-monitoring in cardiovascular disease. Numerous techniques exist such as flow mediated dilation (FMD) $(1,2)$, venous occlusion plethysmography $(3,4)$, pulse-wave analysis (5) and laser Doppler iontophoresis (6). Individually, each technique provides some information on the state of endothelial function in vivo but reflects mainly large artery function; only limited information is conveyed about the body's microcirculatory state. Functional in vivo assessment of the microcirculation is largely limited to invasive technology - e.g. coronary angiography (7) which is not suitable for routine screening. However, novel methods using non-invasive technology such as magnetic resonance imaging and positron emission tomography have shown notable improvements for the assessment of coronary microvasculature (8) but are relatively costly.

In a 2005 review on contemporary methods for assessing endothelial function (9) Alam et al. suggested the retinal vascular bed as suitable for non-invasive in vivo assessment. The ocular circulation is unique because it can be viewed directly and strongly resembles cerebral circulation. Measures of ocular circulation can thus be used as surrogate indices of cerebral circulatory mechanisms $(10,11)$. The focus of Alam's review, however, was on static

\section{Correspondence to:}

Rebekka Heitmar

School of Life and Health Sciences, Aston University

Aston Triangle, B4 7ET, Birmingham, UK

Tel.: +441212043853

E-mail: R.Heitmar1@aston.ac.uk

Received: November 25, 2011

Accepted after major revision: March 18, 2012

Prepublished online: April 26, 2012

doi:10.1160/TH11-11-0810

Thromb Haemost 2012; 107: retinal vessel analysis and the use of parameters such as diameter measurements obtained by single retinal photographs. Since then, numerous groups have investigated dynamic retinal analysis (12) whereby continuous video recordings are made such that vessel parameters can be assessed over time.

Dynamic retinal analysis has the potential to quantify endothelial function noninvasively in vivo over short time periods (usually no more than 5 minutes) by means of continuous vessel diameter measurements $(13,14)$. In order to achieve optimum imaging quality the pupil must firstly be dilated. The retinal vasculature can then be measured many times a second. Non-invasive stimulation methods (e.g. isometric exercise [15-17] and flickering light [18]) can be used to provoke the retinal vessels to react allowing assessment of endothelial function in retinal arterioles and venules before, during and after stimulation. In contrast to most large artery assessments this is less time consuming, less invasive and more convenient for regular followups. This technology enables both structural and dynamic assessment of microcirculation in humans and a plethora of measures have been introduced to quantify the structural and dynamic properties of retinal circulation (see below).

The importance of static retinal vessel analysis with respect to cardiovascular disease has been demonstrated in the results of large population studies (e.g. the Beaver Dam Eye Study [19], the Arteriosclerosis Risk in Community Study [20] and Rotterdam Study [21]). These studies have found that larger retinal venular calibre is associated with an increased risk for stroke (22, 23), reduced arterial wall compliance in large arterial beds is associated with retinal arteriolar narrowing and reduced arterial wall compliance in small arterial beds is associated with retinal venular widening (23). Despite its predictive value for evaluating risk of cardiovascular disease this method only provides a snapshot of an individual's circulatory state. Assessment of the dynamic properties of the circulatory system could provide additional information about endothelial dysfunction and facilitate early diagnosis of related diseases. Hence, this review is focused on describing dynamic retinal diameter assessments and their potential for assessing endothelial function in vivo in humans.

\section{Mechanisms underlying retinal vessel dilation to flicker light (FL) provocation}

The reaction of retinal photoreceptors to different luminance levels alters their metabolic demand thus increasing blood flow in the inner retina. The increased metabolic demand due to the application of flickering light triggers a cascade of reactions. One such reaction is the release of nitric oxide (NO) which dilates retinal vessels. The role of $\mathrm{NO}$ and its role in retinal vasodilation have been studied in detail by changing lactate and glucose levels either by exogenous or endogenous routes $(24,25)$. Intravenous administration of the NO synthase inhibitor $\mathrm{N}_{\mathrm{G}}$-monomethyl-1-Arginine (26) reduces dilatory response of arteries and veins, following flicker-light stimulation, to approximately the level of normal vessel pulsation $(\sim 2-3 \%)$. Collectively these studies showed that blocking NO release blunts the retinal vessel dilatory response and demonstrates the role of NO in controlling retinal vascular tone.

\section{Equipment and provocation protocols}

The only commercially available system capable of continuous measurement of reti- 


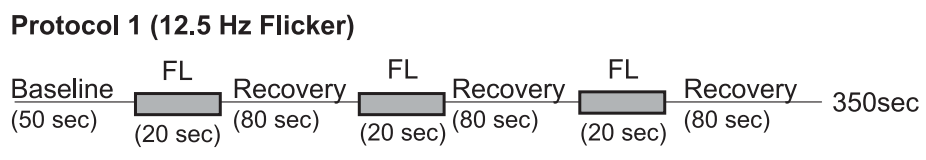

Protocol 2 (8 Hz Flicker)

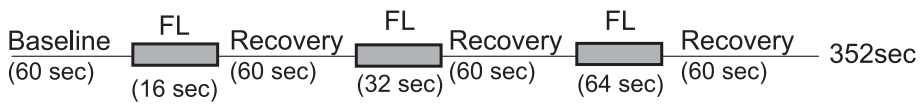

Figure 1: The two FL provocation protocols in common use. Top: $50 \mathrm{~s}$ baseline measurement followed by three cycles of $20 \mathrm{~s}$ flicker and $80 \mathrm{~s}$ recovery. Bottom: $60 \mathrm{~s}$ baseline measurement followed by three cycles of flicker provocation of increasing duration (16 s, $32 \mathrm{~s}$ and $64 \mathrm{~s})$ and a fixed 60 s recovery per cycle.

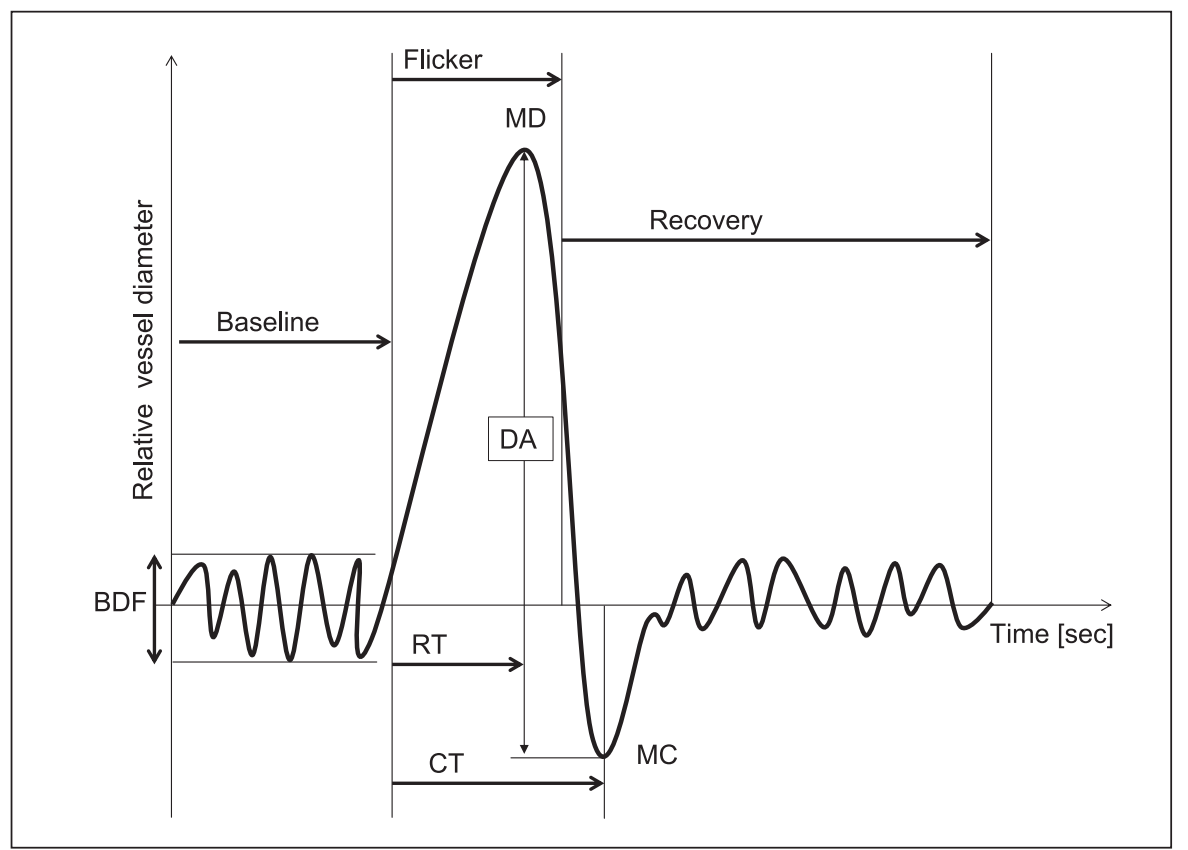

Figure 2: Schematic diagram of a single cycle of retinal vessel diameter recording, before, during and after FL-provocation. Calculation of various spine points is indicated: BDF: baseline diameter fluctuation; MD: maximum dilation; MC: maximum constriction; DA: dilation amplitude; RT: reaction time; $\mathrm{CT}$ : constriction time.

nal vessel diameters is the dynamic Retinal Vessel Analyser by IMEDOS (Imedos, Jena, Germany). This setup comprises the Zeiss FF450 fundus camera, a digital video came$\mathrm{ra}$, and a computer for real-time capture and analysis of the video signal. Flickerlight provocation is achieved by interrupting the fundus illumination using an optoelectronic shutter at a rate of $12.5 \mathrm{~Hz}$. The video camera normally captures the fundus image at $25 \mathrm{~Hz}$; during FL-provocation this drops to $12.5 \mathrm{~Hz}$ (though note Protocol 2 below). The video signal is digitised and can also be stored for later reanalysis. The accompanying software analyses the video signal and estimates the diameter of short sections (up to $\sim 1 \mathrm{~mm}$ ) of selected retinal vessels at a resolution of approximately $12.5 \mu \mathrm{m} /$ pixel.

Currently there is a lack of standardisation in the collection and evaluation of data from dynamic RVA (Retinal Vessel Analyser), resulting in numerous provocation protocols and a bewildering array of data analyses. Recently Garhofer et al. (12) have argued for the need to standardise both the protocols and data analysis to enable better study comparison. Fortunately, the underlying data acquisition has seen the use of only a few different protocols.

\section{Flicker light provocation}

\section{Protocol 1 \\ (or the Standard protocol)}

Due to its incorporation into the Imedos system the most widely used protocol to date is a 350 second (s) continuous video recording of the retinal vasculature comprising $50 \mathrm{~s}$ of baseline measurement followed by three cycles of $12.5 \mathrm{~Hz}$ flicker light (FL) for $20 \mathrm{~s}$ and $80 \mathrm{~s}$ recovery. In the Imedos setup the $12.5 \mathrm{~Hz}$ flicker is generated by an optoelectronic shutter that interrupts the fundus illumination on alternate video frames. Consequently, during flicker, recording only takes place during half of the frames yielding a sampling rate of $12.5 \mathrm{~Hz}$ (27).

\section{Protocol 2}

This protocol uses $8 \mathrm{~Hz}$ flicker generated from a light source that is, additionally, spectrally separate from the fundus illumination. With suitable spectral filtering of the video camera to remove the flicker illumination this setup allows uninterrupted data acquisition (15). Although the length of recording is similar (352 s), studies carried out with this protocol tend to use shorter recovery times (duration between flicker cycles) and increasing flicker durations for each cycle (see Fig. 1).

\section{Isometric exercise}

Provocation of the vascular system using isometric exercise is usually achieved by the participants holding a weight resulting in an increase in systemic blood pressure. This technique has been used to assess the Bayliss effect (28) and also to examine regional differences in regulating vascular tone in diabetes (29). 


\section{Data analysis}

The sheer volume of data from each recording session - up to 80 data points per vessel segment per video frame - has led most researchers to average the measurements over short time frames and along the vessel profile at different stages of the protocol (termed spine point analysis [30]). Recently, Fourier analysis has been used in an attempt to analyse the longitudinal vessel profiles averaged over time only (31). Both the spine point analysis and the Fourier analysis are detailed below.

\section{Spine points and time course analysis}

Usually the diameter readings are averaged over the vessel length and then averaged over 1-s intervals (32). The mean baseline diameter is then computed for $20-30 \mathrm{~s}$ prior to the first flicker and the whole timeseries is normalised such that the diameter readings are expressed as percent of baseline. Several measures have been calculated from this normalised time-series. Initially researchers calculated maximum dilation (MD) and/or maximum constriction (MC) $(30,33)$. Then more complex computations were reported that attempted to characterise the vessel's elastic behaviour such as dilation amplitude (DA) - computed as MD-MC - and baseline diameter fluctuation (BDF) - the maximal range of diameter measurements during baseline $(30,32)$. The time from onset of flicker to the points of $\mathrm{MD}$ and $\mathrm{MC}$, known as reaction time (RT) and constriction time (CT) respectively, have also been used to characterise provocation (32, 34-36). These spine points (see Fig. 2) can be analysed individually for each stimulation cycle or computed as the average over the number of cycles.

A recent additional parameter is area under the curve (AUC) $(37,38)$ at different time periods during the measurement cycle (see Fig. 3), e.g. baseline, flicker, postflicker. This measure, in conjunction with the relevant spine points, e.g. MD and RT, indicates the amount, speed and longevity of the vessel's reaction.

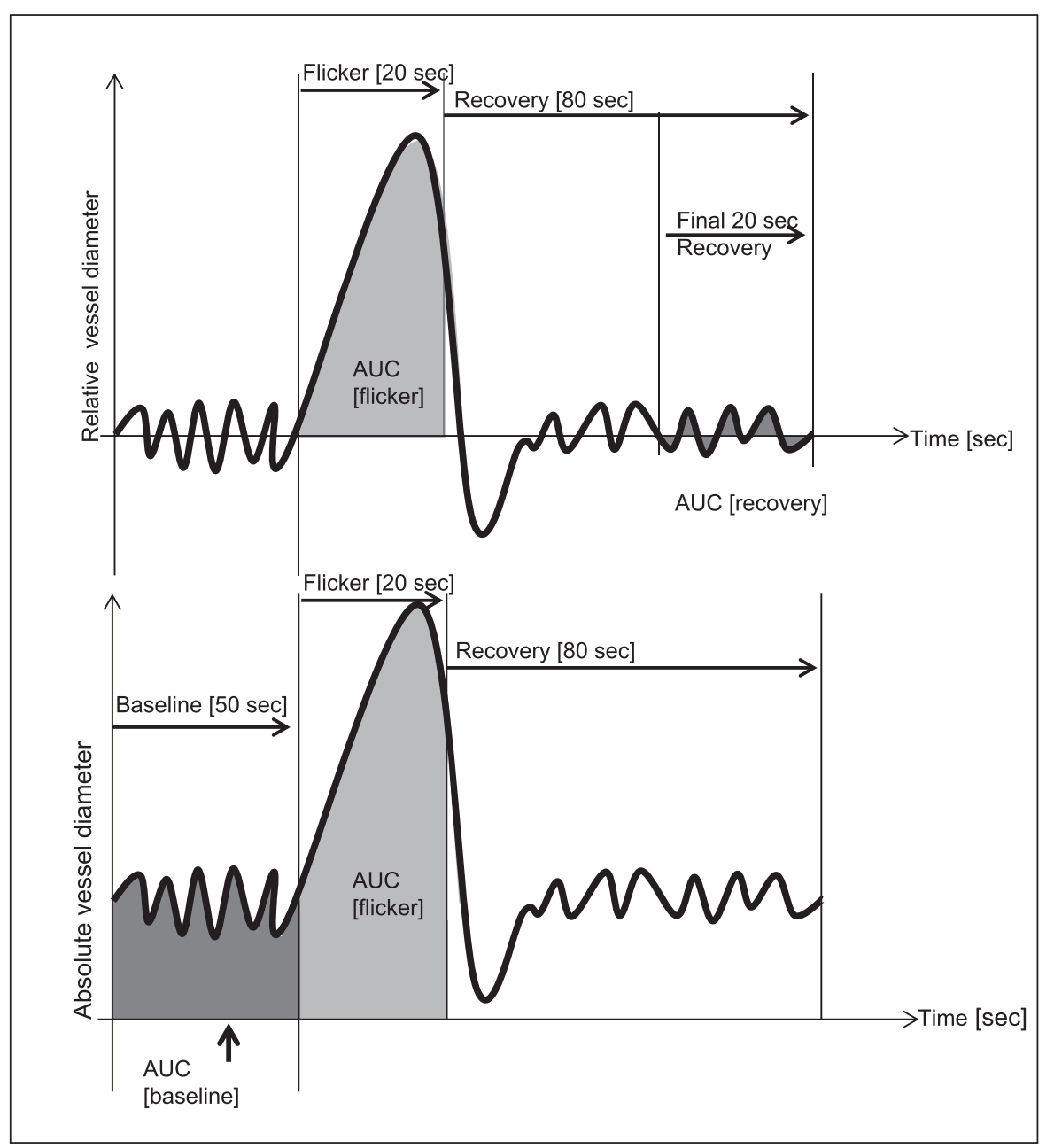

Figure 3: Schematic diagram of a single cycle of retinal vessel diameter recording, before, during and after FL-provocation. Calculation of area under the reaction curve (AUC) for (top) normalised vessel diameters (39) and (bottom) absolute vessel diameters (38) is shown.

\section{Fourier analysis of longitudinal vessel profiles}

Recent work (31) has used Fourier analysis to characterise the structure of vessel segments along their length, collapsed across various time periods. In short, Fourier analysis is used to decompose signals into a series of sine-waves of varying amplitude, frequency and phase. The power spectrum represents the energy (amplitude ${ }^{2}$ ) in the original signal as a function of frequency. The spectral edge frequency (SEF) of the power spectrum of the longitudinal vessel profiles has been used to characterise the micro-structure of the vessel wall $(31,39)$. Increasing SEF indicates increasing energy in the higher-frequency parts of the signal, which could be interpreted as reflecting the degree of roughness of the vessel wall. The SEF has been measured for longitudinal arterial vessel profiles associated with baseline, dilation, constriction and recovery periods of the stimulation cycle in both healthy subjects (31) and HT (39).

\section{Reproducibility and repeatability of RVA measurements}

Without applying any stimulation method, continuous retinal vessel diameter measurements appear to be highly repeatable in healthy subjects in the short term (up to a few days) $(14,40-42)$. Mean sub- 
jects' coefficient of variation (CV) (either from three or four measurements taken over hours or days [14], or of the three cycles of a single measurement $[40,41])$ is usually reported and $\mathrm{CV}$ values lying in the range of $1-5 \%$ are typical $(14,32,40,41)$. However, since each subject's CV is calculated from only three or four measurements the $95 \%$ confidence interval (CI) for $\mathrm{CV}$ is rather large (for four measurements $95 \% \mathrm{CI}=[0.57 \mathrm{xCV}, 3.73 \mathrm{xCV}])$. It is, therefore, almost impossible to infer the repeatability of RVA from these CV.

A more useful measure of reproducibility is the intra-class correlation coefficient $\mathrm{R}_{1}$ or $\mathrm{K}$ which has been reported for shortterm $(<1$ day) and day-to-day (three days) readings (14). $\kappa$ was very high for both short-term $\left(\kappa_{\text {arteries }}=0.96\right.$ and $\left.\kappa_{\text {veins }}=0.98\right)$ and for day-to-day ( $\kappa_{\text {arteries }}=0.87$ and $\left.\kappa_{\text {veins }}=0.90\right)$ measurements. This indicates that, for healthy subjects before FL-provocation, the estimation of vessel diameter is highly reproducible in the short term.

Unfortunately, $\mathrm{k}$ has not been computed for spine-points and we only have limited CV data from three cycles of a single recording session for a limited number of measures. From 21 healthy non-smokers (32), $\mathrm{MC}\left(\mathrm{CV}_{\text {arteries }}=1.2 \%, \mathrm{CV}_{\text {veins }}=0.6 \%\right)$ and $\mathrm{MD}\left(\mathrm{CV}_{\text {arteries }}=1.3 \%, \mathrm{CV}_{\text {veins }}=1.0 \%\right)$ are least variable whilst $\mathrm{RT}$ is very variable $\left(\mathrm{CV}_{\text {arteries }}=30.6 \%, \mathrm{CV}_{\text {veins }}=18.6 \%\right)$. We can find no published data on the repeatability of AUC or spectral analysis.

For healthy patients MD relative to baseline for arteries and veins has been found to lie in the range $\sim 3 \%-7 \%(33,34,43-48)^{1}$ though veins usually dilate slightly more

Note using protocol 2 (43) lower values of MD were found for healthy controls: $1.6 \%$ to $2.8 \%$. than arteries. In CVD patients MD of arteries is in the range $3.1 \%$ to $5.7 \%$ and for veins is $3.6 \%$ to $5 \%(34,49)$. For Diabetes patients MD, which is generally significantly smaller compared with controls, for arteries lies in the range $0.1-2.9 \%$ (dependent on type and presence of retinopathy) and in veins $0.5-4.6 \%(29,44-47)$. For HT patients $\mathrm{MD}$ of arteries values lie in the range $3.6-4.3$ and veins $3.6-6.0 \%$ (find $33,47,48$ ).

\section{Links with well-established measures of vascular endothelial function}

Significant correlations have been found between retinal vessel diameters obtained from static retinal photography and plasma

Table 1: Patients suffering from cardiovascular disease.

\begin{tabular}{|c|c|c|c|c|}
\hline Author & Year & Subjects & Measurements & Main outcome \\
\hline Garhöfer G (43) & 2004 & $\begin{array}{l}24 \text { DM type1 } \\
24 \text { Controls }\end{array}$ & Protocol 2 & $\begin{array}{l}\text { No significant arterial vessel dilation in response to flicker stimulus in DM. } \\
\text { No association with DM duration. }\end{array}$ \\
\hline Mandecka A (44) & 2007 & $\begin{array}{l}172 \text { DM type } 2 \\
68 \text { DM type } 1 \\
53 \text { controls }\end{array}$ & Standard protocol & $\begin{array}{l}\text { Reduced arterial dilation in DM (type } 1 \text { or type } 2 \text { ) compared to controls. } \\
\text { Flicker response in retinal vessels diminished with increasing severity } \\
\text { of diabetic retinopathy. }\end{array}$ \\
\hline Mandecka A (45) & 2009 & $\begin{array}{l}18 \text { DM type } 1 \\
19 \text { controls }\end{array}$ & Standard protocol & $\begin{array}{l}\text { Reduced arterial and venous dilation during flicker stimulation despite } \\
\text { comparable static retinal parameters. }\end{array}$ \\
\hline Nguyen TT (46) & 2009 & $\begin{array}{l}85 \text { DM type } 1 \\
139 \text { DM type } 2 \\
103 \text { controls }\end{array}$ & Standard protocol & $\begin{array}{l}\text { Reduced arterial and venous dilation during flicker stimulation. } \\
\text { Reduced reactivity due to flicker was a significant indicator of DM. }\end{array}$ \\
\hline Pemp B (47) & 2009 & $\begin{array}{l}20 \text { DM type } 1 \\
40 \text { HT } \\
20 \text { controls }\end{array}$ & $\begin{array}{l}60 \text { s baseline; } \\
60 \text { s } 12.5 \mathrm{~Hz} \text { flicker; } \\
120 \text { s recovery. }\end{array}$ & $\begin{array}{l}\text { Reduced dilatory response in retinal vessels in DM and HT compared } \\
\text { to controls. } \\
\text { Brachial artery FMD correlated negatively with FL-induced retinal } \\
\text { dilatory parameters. } \\
\text { No association between retinal dynamic parameters and age was found. }\end{array}$ \\
\hline Pressler A (48) & 2010 & $\begin{array}{l}34 \text { patients after isthmic } \\
\text { coarctation } \\
34 \text { controls }\end{array}$ & Standard protocol & $\begin{array}{l}\text { Retinal arterial diameter assessed by static photography after isthmic } \\
\text { coarctation significantly reduced. } \\
\text { No functional difference (MD, MC) between patients and controls } \\
\text { measured with RVA. }\end{array}$ \\
\hline Heitmar R (34) & 2011 & $\begin{array}{l}24 \text { CAD patients } \\
30 \text { controls }\end{array}$ & Standard protocol & $\begin{array}{l}\text { Reduced RT and CT in retinal arterioles to flicker stimulation in CAD } \\
\text { patients. }\end{array}$ \\
\hline Jensen PS (29) & 2011 & $\begin{array}{l}17 \text { patients with diabetic } \\
\text { maculopathy } \\
17 \text { patients with periphe- } \\
\text { ral diabetic retinopathy } \\
17 \text { controls }\end{array}$ & $\begin{array}{l}3 \text { protocols (isometric } \\
\text { exercise, flicker, and } \\
\text { isometric exercise with } \\
\text { flicker) }\end{array}$ & $\begin{array}{l}\text { Significant difference in arteriole diameter due to isometric exercise } \\
\text { or FL-provocation between all three groups. }\end{array}$ \\
\hline
\end{tabular}


Table 2: Individuals at risk of developing cardiovascular disease.

\begin{tabular}{|l|l|l|l|l}
\hline Author & Year & Subjects & Measurements & Main outcome \\
\hline Reimann M (49) & 2009 & $\begin{array}{l}21 \text { hypercholesterolaemic } \\
\text { patients }\end{array}$ & Standard protocol & $\begin{array}{l}\text { Reduced retinal arteriolar and venular reactivity to flicker provocation. } \\
\text { Increased venous reactivity after single LDL apheresis (attributed to } \\
\text { larger baseline diameter in veins rather than LDL apheresis per se). }\end{array}$ \\
\hline Heitmar R (32) & 2010 & $\begin{array}{l}78 \text { healthy controls } \\
21 \text { otherwise healthy } \\
\text { smokers }\end{array}$ & Standard protocol & $\begin{array}{l}\text { Significantly increased level of arterial baseline diameter fluctuation } \\
\text { before flicker stimulation in smokers. } \\
\text { Significantly increased stiffness of retinal arterioles in smokers than } \\
\text { non-smokers. }\end{array}$ \\
\hline Kotliar KE (37) & 2011 & $\begin{array}{l}46 \text { obese volunteers } \\
46 \text { controls }\end{array}$ & Standard protocol & $\begin{array}{l}\text { Reduced retinal vessel dilatory response in obese patients. } \\
\text { Increased RT of arterioles for obese patients. } \\
\text { Correlation between AUC 50-80 s after FL and waist circumference. }\end{array}$ \\
\hline Patel S (36) & 2011 & $\begin{array}{l}45 \text { healthy White Euro- } \\
\text { peans (WE) } \\
45 \text { healthy South Asians } \\
\text { (SA) }\end{array}$ & Standard protocol & $\begin{array}{l}\text { South Asians had higher fasting triglyceride and lower HDL levels than } \\
\text { Western Europeans. } \\
\text { Arterial RT positively correlated with measured plasma TG levels only in } \\
\text { SA. }\end{array}$ \\
\hline
\end{tabular}

Table 3: Effect of age upon dynamic retinal vessel parameters.

\begin{tabular}{l|l|l|l|l}
\hline Author & Year & Subjects & Measurements & Main outcome \\
\hline Kotliar KE (31) & 2008 & $\begin{array}{l}33 \text { healthy } \\
\text { volunteers }\end{array}$ & $\begin{array}{l}\text { Two cycles of: } \\
100 \mathrm{~s} \text { baseline; } \\
60 \mathrm{~s} 12.5 \mathrm{~Hz} \text { flicker; } \\
150 \mathrm{~s} \text { recovery. }\end{array}$ & $\begin{array}{l}\text { Correlation between an index thought to be related to arterial-wall } \\
\text { roughness and age of participants. }\end{array}$ \\
\hline Kneser M (54) & 2009 & $\begin{array}{l}52 \text { healthy } \\
\text { volunteers } \\
\text { Averaged spine point } \\
\text { analysis }\end{array}$ & $\begin{array}{l}\text { Standard protocol } \\
\text { volunteers }\end{array}$ & Reduced arterial dilation to flicker provocation in older participants. \\
\hline Heitmar R (32) & 2010 & Standard protocol & $\begin{array}{l}\text { No relationship between MD, MC, DA, RT, CT (etc) of individual flicker } \\
\text { cycles and age. }\end{array}$ \\
\hline
\end{tabular}

markers of endothelial function (20) and retinopathy $(50,51)$ but not FMD $(52)$. Static retinal vessel analysis has also revealed a significant correlation between a reduction in FMD and the diameter of wider retinal veins but not arteries (53). The different results for arteries and veins were attributed to differences in regulation of macro- and micro-circulation and the uniqueness of the retinal circulation. However, the lack of an association could also be due to the comparison between a method that captures dynamic properties (FMD) with one that does not (retinal photography).

Correlations have been found between FMD and FL-induced arteriolar (but not venular) dilation in controls, diabetic patients and HT patients (47). The correlation was weak but significant (Perason's $r=0.3, p=0.044)$, perhaps due to the data being pooled over all participants that limited the strength of the analysis. However, this is evidence that dynamic retinal vessel assessment is capturing functional properties of the vascular system.

So far, no firm conclusions can be drawn regarding a correlation between measurements of large arteries and retinal endothelial measurements. This does not mean, however, that there is no connection. The vessel morphology of micro- and macrocirculation differs along with their regulatory mechanisms. Systemic blood pressure regulation depends on both macro- and micro-circulation in order to function normally; an imbalance in one system could influence the other.

\section{Overview of current studies using continuous retinal diameter measurements}

The different studies relevant for assessing endothelial function in systemic disease have been summarised in Tables 1-4 and are described further in the following section.

\section{Value of assessing micro- circulatory parameters of endothelial function}

Continuous retinal vessel diameter measurements have been widely applied to assess endothelial function in diabetes mellitus (29, 43-45), hypertension $(31,33,47$, $48)$, obesity (37), smoking $(32,57)$, coron- 
Table 4: Patients suffering from peripheral vasospasm and ocular vascular abnormalities.

\begin{tabular}{|l|l|l|l|l}
\hline Author & Year & Subjects & Measurements & Main outcome \\
\hline Branca F (55) & 2005 & $\begin{array}{l}30 \text { healthy volunt- } \\
\text { eers (15 with peripheral } \\
\text { vasospasm) }\end{array}$ & $\begin{array}{l}60 \text { s baseline measure- } \\
\text { ment only } \\
\text { (2 visits: } 1 \text { week apart) }\end{array}$ & $\begin{array}{l}\text { No difference in baseline measurements between groups. } \\
\text { Good repeatability across visits of single baseline diameter measure- } \\
\text { ments in arteries and veins. }\end{array}$ \\
\hline Gugleta K (56) & 2006 & $\begin{array}{l}\text { 24 healthy volun- } \\
\text { teers (14 with peripheral } \\
\text { vasospasm) }\end{array}$ & $\begin{array}{l}\text { Standard protocol } \\
\text { Dilatory response augmentation seen in healthy but not } \\
\text { vasospastic subjects. } \\
\text { Reduced arteriole and venule dilation to FL (in distal and proximal } \\
\text { vessels). }\end{array}$ \\
\hline Lanzl IM (35) & 2010 & $\begin{array}{l}10 \text { AMD patients } \\
10 \text { controls }\end{array}$ & Standard protocol & $\begin{array}{l}\text { Diminished arteriolar and venular response to FL provocation in AMD } \\
\text { patients compared to controls. } \\
\text { No change in vessel reactivity after single dose of VEGF } \\
\text { inhibitor. }\end{array}$ \\
\hline Gugleta K (38) & 2011 & $\begin{array}{l}47 \text { POAG } \\
46 \text { OHT } \\
56 \text { controls }\end{array}$ & Standard protocol & $\begin{array}{l}\text { Differences in inferior and superior retinal vessel reactivity. } \\
\text { POAG patients had lower reactivity. }\end{array}$ \\
\hline
\end{tabular}

ary artery disease (34) and ocular/ vascular dysregulation $(38,55,56)$. Many of these studies link a diminished retinal vascular response or delayed provocation reactivity with endothelial dysfunction. Although there is overwhelming evidence that the mechanisms underlying vascular dilation to FL provocation reflect endothelial function $(27,44,58)$, thus far few studies have found a link between established markers of endothelial function and FL provocation $(20,47,51-53)$. In these groups, the presence of an imbalance of vasoconstrictive and vasodilatory factors implies endothelial dysfunction. Further research is needed with larger sample sizes and proper control of confounding factors such as the use of consistent acquisition times.
The autonomic nervous system is also believed to be involved in the regulation of vascular reactivity in the eye $(43,59)$. Patients suffering from primary Raynaud's Syndrome have normal FMD values (60) but significant abnormalities in their microcirculation $(60,61)$; micro- and macro-vessel endothelial dysfunction need not occur simultaneously. Assessment of one vascular bed provides only limited and possibly misleading information about the whole vascular system.

Differences in the regulation of vascular tone between central and peripheral retinal arterioles have been shown in patients suffering from DM but presenting with regionally different diabetic eye disease (29). This local difference in DM highlights the

\begin{tabular}{|c|c|c|}
\hline \multicolumn{3}{|c|}{ Appendix: Spine point terminology } \\
\hline Parameter & Description & Calculation \\
\hline BDF & Baseline Diameter Fluctuation & Maximum amplitude during baseline \\
\hline BfR & Baseline corrected flicker Response & $\mathrm{BfR}=\mathrm{DA}-\mathrm{BDF}$ \\
\hline DA & Dilation Amplitude & $M D-M C$ \\
\hline$\Delta \mathrm{D}$ & $\begin{array}{l}\text { Vessel diameter increase after flicker } \\
\text { initiation to the point where MD is } \\
\text { reached }\end{array}$ & $\begin{array}{l}\text { MD - } 1 \mathrm{~s} \text { mean baseline diameter (prior to flicker } \\
\text { initiation) }\end{array}$ \\
\hline MD & Maximum Dilation & $\begin{array}{l}\text { Maximum diameter following onset of flicker light } \\
\text { provocation }\end{array}$ \\
\hline MC & Maximum Constriction & Minimum diameter after MD \\
\hline RT & Reaction Time & Time (seconds) to reach MD after flicker initiation \\
\hline CT & Constriction Time & Time (seconds) to reach MC after flicker initiation \\
\hline $\mathrm{AU}(\mathrm{R}) \mathrm{C}$ & Area Under the (Reaction) Curve & $\begin{array}{l}\text { Integration of diameter measurements over spe- } \\
\text { cific time period }\end{array}$ \\
\hline
\end{tabular}

need for assessing different vascular beds and use methodologies capable of evaluating differences in regulatory mechanisms. Therefore, the assessment of endothelial function at multiple vascular beds can highlight differences in the underlying pathophysiology. Microalbuminuria, also a marker of endothelial function, has shown to correlate with arterial dilation in healthy obese adolescents, but not in DM type I (62). However, retinal vascular changes do not necessarily occur at the same time as vascular changes in the renal system (63).

In summary, dynamic retinal vessel diameter assessment using FL and/or isometric exercise provocation is most likely a surrogate measure of endothelial function at the microcirculatory level, though note that there is no long-term data concerning the value of RVA measures in predicting future CVD events. It is, however, essential to be aware of its test re-test variability (41, 42). A carefully devised measurement protocol in conjunction with large-artery endothelial assessment should provide a more comprehensive picture of vascular health.

\section{Acknowledgements}

RJS is supported by an EPSRC grant to Prof. Tim Meese.

\section{Conflicts of interest}

None declared. 


\section{References}

1. Leeson P, Thorne S, Donald A, et al. Non-invasive measurement of endothelial function: effect on brachial artery dilation of graded endothelial dependent and independent stimuli. Heart 1997; 78: 22-27.

2. Corretti MC, Anderson TJ, Benjamin EJ, et al. Guidelines for the ultrasound assessment of endothelial-dependent flow-mediated vasodilation of the brachial artery: a report of the international brachial artery reactivity task force. J Am Coll Cardiol 2002; 39: 257-265.

3. Panza JA, Quyyumi AA, Brush Jr JE, et al. Abnormal endothelium dependent vascular relaxation in patients with essential hypertension. N Engl J Med 1990; 323: 22-27.

4. Chowienczyk PJ, Watts GF, Cockcroft JR, et al. Impaired endothelium-dependent vasodilation of forearm restistance vessels in hypercholesterolaemia. Lancet 1992; 340: 1430-1432.

5. Wilkinson IB, McEniery CM. Arterial stiffness, endothelial function and novel pharmacological approaches. Clin Exp Pharmacol Physiol 2004; 31: 795-799.

6. Ozbebit FY, Esen F, Gulec S, et al. Evaluation of forearm microvascular blood flow regulation by laser Doppler flowmetry, iontophoresis, and curve analysis: contribution of axon reflex. Microvasc Res 2004; 67: 207-214.

7. Ludmer PL, Selwyn AP, Shook TL, et al. Paradoxical vasoconstriction induced by acetylcholine in atherosclerotic coronary arteries. N Engl J Med 1986; 315: 1046-1051.

8. Prior JO, Schindler TH, Facta AD, et al. Determinants of myocardial blood flow response to cold pressor testing an pharmacologic vasodilation in healthy humans. Eur J nucl Med Mol Imaging 2007; 34: 20-27.

9. Alam TA, Seilfalian AM, Baker D. A review of methods currently used for assessment of in vivo endothelial function. Eur J Vasc Endovasc Surg 2005; 29: 269-276.

10. Steuer H, Jaworski A, Elger B, et al. Functional characterization and comparison of the outer bloodretina barrier and the blood-brain barrier. Invest Ophthalmol Vis Sci. 2005; 46: 1047-1053.

11. Patton N, Aslam T, Macgillivray T, et al. Retinal vascular image analysis as a potential screening tool for cerebrovascular disease: a rationale based on homology between cerebral and retinal microvasculatures. J Anat 2005; 206: 319-348.

12. Garhöfer G, Bek T, Boehm AG, et al; Ocular Blood Flow Research Association. Use of the retinal vessel analyzer in ocular blood flow research. Acta Ophthalmol. 2010; 88: 717-722.

13. Seifertl BU, Vilser W. Retinal Vessel Analyzer (RVA)--design and function. Biomed Tech (Berl) 2002; 47 (Suppl 1): 678-681.

14. Polak K, Dorner G, Kiss B, Polska E, et al. Evaluation of the Zeiss retinal vessel analyser. Br J Ophthalmol 2000; 84: 1285-1290.

15. Jeppesen P, Gregersen PA, Bek T. The age-dependent decrease in the myogenic response of retinal arterioles as studied with the Retinal Vessel Analyzer. Graefes Arch Clin Exp Ophthalmol 2004; 242: 914-919.

16. Jeppesen P, Sanye-Hajari J, Bek T. Increased blood pressure induces a diameter response of retinal ar- terioles that increases with decreasing arteriolar diameter. Invest Ophthalmol Vis Sci 2007; 48: 328-331.

17. Luksch A, Wimpissinger B, Polak K, et al. ETa-receptor blockade, but not ACE inhibition, blunts retinal vessel response during isometric exercise. Am J Physiol Heart Circ Physiol 2006; 290: H1693-1698.

18. Polak K, Schmetterer L, Riva CE. Influence of flicker frequency on flicker-induced changes of retinal vessel diameter. Invest Ophthalmol Vis Sci 2002; 43: 2721-2726.

19. Klein R, Klein BE, Knudtson MD, et al. Are inflammatory factors related to retinal vessel caliber? The Beaver Dam Eye Study. Arch Ophthalmol 2006; 124: 87-94.

20. Klein R, Sharrett AR, Klein BE, et al. Are retinal arteriolar abnormalities related to atherosclerosis? The Atherosclerosis Risk in Communities study. Aterioscler Thromb Vasc Biol 2000; 20: 1644-1650.

21. Wieberdink RG, Ikram MK, Koudstaal PJ, et al. Retinal vascular calibers and the risk of intracerebral hemorrhage and cerebral infarction: the Rotterdam Study. Stroke 2010; 41: 2757-2761.

22. Cheung N, Islam FM, Jacobs DR Jr, et al. Retinal vascular caliber and extracranial carotid disease in patients with acute ischemic stroke: the Multi-Centre Retinal Stroke (MCRS) study. Arterial compliance and retinal vascular caliber in cerebrovascular disease. Ann Neurol 2007; 62: 618-624.

23. De Silva DA, Liew G, Wong MC, et al. Retinal vascular caliber and extracranial carotid disease in patients with acute ischemic stroke: the Multi-Centre Retinal Stroke (MCRS) study. Stroke 2009; 40: 3695-3699.

24. Garhöfer G, Zawinka C, Huemer KH. Flicker lightinduced vasodilatation in the human retina: effect of lactate and changes in mean arterial pressure. Invest Ophthalmol Vis Sci 2003; 44: 5309-5314.

25. Dorner GT, Garhofer G, Huemer KH. Hyperglycemia affects flicker induced vasodilation in the retina of healthy subjects. Vis Res 2003; 43: 1495-1500.

26. Lasta M, Polak K, Luksch A. Effect of NO synthase inhibition on retinal vessel raction to isometric exercise in healthy humans. Acta Ophthalmol 2010; doi:10.1111/j.1755-3768.2010.01970.x.

27. Vilser W, Nagel E, Lanzl I. Retinal Vessel Analysis New Possibilities. Biomed Tech (Berlin) 2002; 47 (Suppl 1): 682-685.

28. Blum M, Bachmann K, Wintzer D. Noninvasive measurement of the Bayliss effect in retinal autoregulation. Graefe's Arch Clin Exp Ophthalmol 1999; 237: 296-300.

29. Skov Jensen P, Jeppesen P, Bek T. Differential diameter responses in macular and peripheral retinal arterioles may contribute to the regional distribution of diabetic retinopathy lesions. Graefes Arch Clin Exp Ophthalmol 2011; 249: 407-412.

30. Nagel E, Vilser W, Lanzl I. Age, blood pressure, and vessel diameter as factors influencing the arterial retinal flicker response. Invest Ophthalmol Vis Sci 2004; 45: 1486-1492.

31. Kotliar KE, Mücke B, Vilser W, et al. Effect of aging on retinal artery blood column diameter measured along the vessel axis. Invest Ophthalmol Vis Sci 2008; 49: 2094-2102.

32. Heitmar R, Blann AD, Cubbidge RP, et al. Continuous retinal vessel diameter measurements: the future in retinal vessel assessment? Invest Ophthalmol Vis Sci 2010; 51: 5833-5839.
33. Nagel E, Vilser W, Fink A, et al. Blood pressure effects on retinal vessel diameter and flicker response: a 1.5-year follow-up. Eur J Ophthalmol 2006; 16 : $560-565$.

34. Heitmar R, Cubbidge RP, Lip GY, et al. Altered blood vessel responses in the eye and finger in coronary artery disease. Invest Ophthalmol Vis Sci 2011; 52: 6199-6205.

35. Lanzl IM, Seidova SF, Maier M, et al. Dynamic retinal vessel response to flicker in age-related macular degeneration patients before and after vascular endothelial growth factor inhibitor injection. Acta Ophthalmol 2011; 89: 472-479.

36. Patel SR, Bellary S, Qin L, et al. Abnormal retinal vascular function and lipid levels in a sample of healthy UK South Asians. Br J Ophthalmol 2011; 95 : 1573-1576.

37. Kotliar KE, Lanzl IM, Schmidt-Trucksäss A, et al. Dynamic retinal vessel response to flicker in obesity: A methodological approach. Microvasc Res 2011; 81: 123-128.

38. Gugleta K, Kochkorov A, Waldmann N, et al. Dynamics of retinal vessel response to flicker light in glaucoma patients and ocular hypertensives. Graefes Arch Clin Exp Ophthalmol 2012; 250: 589-594.

39. Kotliar K, Nagel E, Vilser W, et al. Microstructural alterations of retinal arterial blood column along the vessel axis in systemic hypertension. Invest Ophthalmol Vis Sci 2010; 51: 2165-2172.

40. Pache M, Nagel E, Flammer J. Reproducibility of measurements with the retinal vessel analyzer under optimal conditions. Klin Monbl Augenheilkd 2002; 219: 523-527.

41. Nagel E, Vilser W, Fink A. Varianz der Netzhautgefaessreaktion auf Flickerlicht. Ophthalmologe 2006; 103: 114-119.

42. Nguyen TT, Kreis AJ, Kawasaki R, et al. Reproducibility of the Retinal Vascular Response to Flicker Light in Asians. Curr Eye Res 2009; 34: 1082-1088.

43. Garhöfer G, Zawinka C, Resch H, et al. Reduced response of retinal vessel diameters to flicker stimulation in patients with diabetes. Br J Ophthalmol 2004; 88: 887-891.

44. Mandecka A, Dawczynski J, Blum M, et al. Influence of flickering light on the retinal vessels in diabetic patients. Diabetes Care 2007; 30: 3048-3052.

45. Mandecka A, Dawczynski J, Vilser W, et al. Abnormal retinal autoregulation is detected by provoked stimulation with flicker light in well-controlled patients with type 1 diabetes without retinopathy. Diabetes Res Clin Pract 2009; 86: 51-55.

46. Nguyen TT, Kawasaki R, Wang JJ, et al. Flicker lightinduced retinal vasodilation in diabetes and diabetic retinopathy. Diabetes Care 2009; 32: 2075-2080.

47. Pemp B, Weigert G, Karl K, et al. Correlation of flicker-induced and flow-mediated vasodilatation in patients with endothelial dysfunction and healthy volunteers. Diabetes Care 2009; 32: 1536-1541.

48. Pressler A, Esefeld K, Scherr J, et al. Structural alterations of retinal arterioles in adults late after repair of aortic isthmic coarctation. Am J Cardiol 2010; 105: 740-744.

49. Reimann M, Prieur S, Lippold B, et al. Retinal vessel analysis in hypercholesterolemic patients before and after LDL apheresis. Atheroscler Suppl 2009; 10: $39-43$. 
50. Van Hecke MV, Dekker JM, Nijpels G, et al. Inflammation and endothelial dysfunction are associated with retinopathy: the Hoorn Study. Diabetologia 2005; 48: 1300-1306.

51. Matsumoto K, Sera Y, Ueki Y, et al. Comparison of serum concentrations of soluble adhesion molecules in diabetic microangiopathy and macroangiopathy. Diabetic Med 2002; 19: 822-826.

52. Van Hecke MV, Dekker JM, Nijpels G, et al. Are retinal microvascular abnormalities associated with large artery dendothelial dysfunction And intima media thickness? The Hoorn Study. Clin Sci 2006; 110: 597-604.

53. Nguyen TT, Islam A, Farouque HMO, et al. Retinal vascular caliber and brachial flow-mediated dilation: The Multi-Ethnic Study of Atherosclerosis. Stroke 2010; 41: 1343-1348.

54. Kneser M, Kohlmann T, Pokorny J, et al. Age related decline of microvascular regulation measured in healthy individuals by retinal dynamic vessel analysis. Med Sci Monit 2009; 15: CR436-441.

55. Branca F, Orgül S, Zawinka C, et al. Retinal vascular diameter in young subjects with a vasospastic propensity. Graefes Arch Clin Exp Ophthalmol 2006; 244: 454-459.

56. Gugleta K, Zawinka C, Rickenbacher I, et al. Analysis of retinal vasodilation after flicker light stimulation in relation to vasospastic propensity. Invest Ophthalmol Vis Sci 2006; 47: 4034-4041.

57. Garhöfer G, Resch H, Sacu S, et al. Effect of regular smoking on flicker induced retinal vasodilatation in healthy subjects. Microvasc Res 2011; 82: 351-355.

58. Delles C, Michelson G, Harazny J, et al. Impaired endothelial function of the retinal vasculature in hypertensive patients. Stroke 2004; 35: 1289-1293.

59. Flammer J, Mozaffarieh M. Autoregulation, a balancing act between supply and demand. Can J Ophthalmol 2008; 43: 317-321.
60. Roustit M, Simmons GH, Baguet JP, et al. Discrepancy between simultaneous digital skin microvascular and brachial artery macrovascular post-occlusive hyperemia in systemic sclerosis. J Rheumatol 2008; 35: 1576-1583.

61. Roustit M, Blaise S, Millet C, et al. Impaired transient vasodilation and increased vasoconstriction to digital local cooling in primary Raynaud's phenomenon. Am J Physiol Heart Circ Physiol 2011; 301: H324-330.

62. Schiel R, Vilser, W, Kovar, F, et al. Retinal vessel response to flicker light in children and adolescents with type 1 diabetes mellitus and overweight or obesity. Diabetes Res Clin Pract 2009; 83: 358-364.

63. Wolf G, Müller N, Mandecka A, et al. Association of diabetic retinopathy and renal function in patients with types 1 and 2 diabetes mellitus. Clin Nephrol 2007; 68: 81-86. 